Brit. Heart F., 1966, 28, 161.

\title{
Electrode Catheters and the Diagnosis of Ebstein's Anomaly of the Tricuspid Valve
}

\author{
HAMISH WATSON \\ From the Department of Medicine in the University of St. Andrews and the Department of Cardiology in the \\ Royal Infirmary, Dundee
}

\begin{abstract}
Ebstein's anomaly of the tricuspid valve, originally described in 1866, remained, until recently, a pathological curiosity, and only some 26 cases had been reported when Tourniaire, Deyrieux, and Tartulier published the first account of one diagnosed clinically in 1949 . During the past 15 years, in which there has been widespread interest in all types of congenital heart disease, Ebstein's anomaly has perhaps received rather more than its fair share of attention, with the result that few centres cannot now produce a small collection of patients with this malformation.
\end{abstract}

Its clinical and electrocardiographic features have been carefully documented and regularly reviewed by many authors, amongst the most recent of whom are Vacca, Bussmann, and Mudd (1958) and Schiebler et al. (1959), and there is at present little difficulty in recognizing the characteristic physical signs in the typical case with cardiomegaly. There is, however, a wide scatter in the clinical picture, which sometimes bears little resemblance to the socalled classical case, and it is not always easy to make a bedside diagnosis, especially in those with small hearts, where the differential diagnosis between Ebstein's anomaly and a cardiomyopathy of one sort or another may be extremely difficult.

This may not have mattered greatly when diagnosis was merely of academic interest, but now that attempts are being made to treat the condition surgically (Glenn, 1958; Gasul et al., 1959; Schiebler et al., 1959; McGredie et al., 1962; Barnard and Schrire, 1963; Reed, Kittle, and Heilbrunn, 1963; Scott et al., 1963; Cartwright et al., 1964; Hardy et al., 1964; Lillehei and Gannon, 1964; Bahnson, Bauersfeld, and Smith, 1965; Lillehei and Gannon, 1965), an accurate pre-operative assessment of the exact nature and severity of the lesion has assumed considerable importance, as patients with Ebstein's

Received May 17, 1965. anomaly are notoriously bad operative risks (Engle et al., 1950; Broadbent et al., 1953; Gasul et al., 1953; Goodwin, Wynn, and Steiner, 1953; Lev, Gibson, and Miller, 1955; Kilby et al., 1956; Caddell and Browne, 1963).

Though cardiac catheterization and angiocardiography may be helpful and yield valuable information, in many patients no intracardiac investigations have been carried out because of repeated warnings about the dangers of these procedures in such patients (Baker, Brinton, and Channell, 1950; Engle et al., 1950; Schaede, 1951; Blacket et al., 1952; Campbell, 1953; Kjellberg et al., 1955; Brown, Heath, and Whitaker, 1956; Wood, 1956; Mayer, Nadas, and Ongley, 1957); in addition there is a lack of detailed knowledge about the haemodynamic effects peculiar to this lesion. While there is no doubt that catheterization carries a greater risk in these circumstances, increased experience of investigative techniques in general, plus improved methods of dealing with rapid paroxysmal tachycardia and cardiac arrest, have made it much less hazardous than it used to be. Provided that the examination is performed by skilled workers who understand the dangers involved and who are properly equipped to deal with the emergencies that are likely to arise, there is no reason why those with Ebstein's anomaly should not be investigated in the same way as those with any other serious congenital cardiac lesion for whom surgery is contemplated.

Of the intracardiac aids to diagnosis that may be helpful, the best known and most commented upon is the electrode catheter, which, though of great value during routine cardiac catheterization (Watson, 1964), was not widely used in diagnostic work until Clark and Bargeron (1959) reported the detection of left-to-right shunts with a platinum electrode when hydrogen was used as an indicator. Since then, Sodi-Pallares'suggestion that there might 
be a possibility of diagnosing Ebstein's anomaly of the tricuspid valve by means of intracavitary leads (Sodi-Pallares and Marsico, 1955; Sodi-Pallares et $a l ., 1954)$ has been widely adopted, and there is no doubt that this idea, which was further elaborated in classical papers by Hernandez, Rochkind, and Cooper (1958) and Yim and Yu (1958), is a most useful test. It does have limitations, however, and both false positive (Gandhi and Datey, 1963) and false negative (Moles, Jacoby, and McIntosh, 1964) records have been reported.

Gandhi and Datey (1963) in an analysis of tracings made as an electrode catheter was withdrawn from the right ventricle into the right atrium in 40 patients, some with and some without heart disease, thought that when withdrawal occurred at low atrial levels, the results might be fallacious. Moles and his colleagues (1964) demonstrated that a normal intracardiac electrocardiographic and pressure relationship might be present in a patient with Ebstein's anomaly when the catheter was withdrawn across the tricuspid valve at mid-atrial level and suggested that this might be because the anterior leaflet was attached to the true annulus along its medial aspect. Illustrating a positive record from the same patient, in which a right ventricular type electrocardiogram and an atrial pressure pulse appeared simultaneously, they stressed the need for careful exploration of the tricuspid area. Both groups re-emphasized the importance of defining the relationship of such changes, and also, if possible, the position of the tricuspid valve, to the spine in the postero-anterior view of the heart during radiography.

Despite the fact that the simultaneous recording of the intracardiac electrocardiogram and pressure pulse is of proved value in a great variety of ways during cardiac catheterization (Goodale et al., 1949; Ferrer et al., 1949; Giraud et al., 1951; Steinberg, Kroop, and Grishman, 1952; Emslie-Smith, 1955; Emslie-Smith, Lowe, and Hill, 1956; Dickens and Goldberg, 1958; Dickens, Maranhao, and Goldberg, 1959; Dickerson and Caris, 1959; Bertrand, Zohman, and Williams, 1959; Watson et al., 1960; Watson and Lowe, 1962; Watson, 1962; Watson, 1964; Watson, Breckenridge, and Lowe, 1964; Watson and Lowe, 1965), Ebstein's anomaly appears to be the one condition in which its use has fired the imagination. Electrode catheters are therefore being used, when this malformation is suspected, by many who have little other experience of recording electrocardiograms inside the heart, and the diagnosis is often "confirmed" on very slender evidence.

The purpose of this communication is to point out some of the changes that may be expected in the normal course of events, when an electrode catheter is withdrawn from the right ventricle into the right atrium, and to emphasize a few of the pitfalls that await those who may be tempted to rely upon this as the definitive method in the diagnosis of Ebstein's anomaly. These observations are based on serial studies over the past 10 years, during which thousands of withdrawal tracings have been made across the tricuspid valve with electrode catheters in more than 700 patients with congenital or acquired heart disease, 6 of whom had Ebstein's anomaly.

The intracardiac electrocardiographic diagnosis of Ebstein's anomaly is based upon two essential features of cavity potentials. The first is that when an electrode catheter is withdrawn from the pulmonary artery through the right heart, certain characteristic changes take place in the intracardiac electrocardiogram, which help to locate its tip if they are correlated with a simultaneously recorded pressure pulse. There is usually a striking alteration in the morphology of the complexes as the electrode passes backwards from the thick muscular-walled cavity of the ventricle into the thinwalled atrial chamber. As can be seen in Fig. 1, the voltage of the QRS complexes is greatly reduced, and the $P$ waves, which in the ventricles are similar to those in surface scalar leads, become relatively large and are often the main deflections. This change coincides with the transition from ventricular to atrial pressure pulses, and for practical purposes pinpoints the site of the tricuspid valve on the oscilloscope during cardiac catheterization or on photographic records taken during the procedure. By this method it is usually possible to make a fairly accurate estimate of the position of the tricuspid valve inside the cardiac silhouette on the $x$-ray screen during fluoroscopy.

Thus, on withdrawal in Ebstein's anomaly, where the first part of the right ventricle has become atrialised, the electrode at the tip of the catheter will continue to record right ventricular potentials after the pressure pulse has changed from a ventricular to an atrial wave form, and this change will take place well to the left of the spine. Furthermore, under these peculiar cirumstances, there will be no change in the pressure pulse at the point where the morphology of the intracardiac electrocardiogram alters when the true right atrium is entered. The end result is a tracing upon which there are three distinct zones. Examples of each, from a case of Ebstein's anomaly, are illustrated in Fig. 2, where normal right ventricular and right atrial records, in which the pressure pulse matches the intracardiac electrocardiogram, are separated by an intermediate area in which it does not.

That such records may be obtained during cardiac 


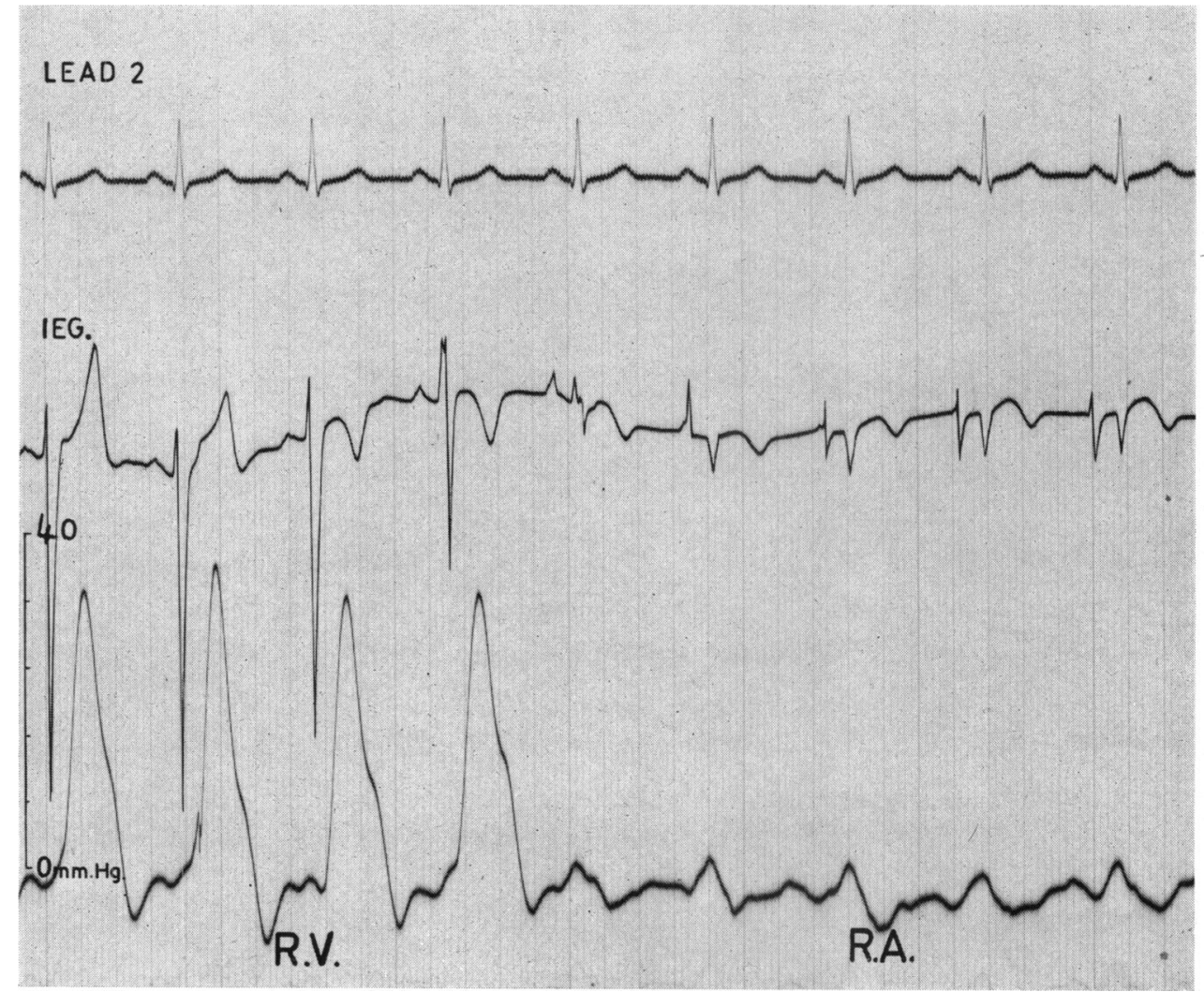

FIG. 1.-This demonstrates the change that normally occurs in the intracardiac electrocardiogram when an electrode catheter is withdrawn from the right ventricle into the right atrium. The voltage of the QRS complexes is greatly reduced and the $\mathbf{P}$ waves become relatively large. This change coincides with the transition from ventricular to atrial pressure pulse waves, and pinpoints the site of the tricuspid valve on the record.

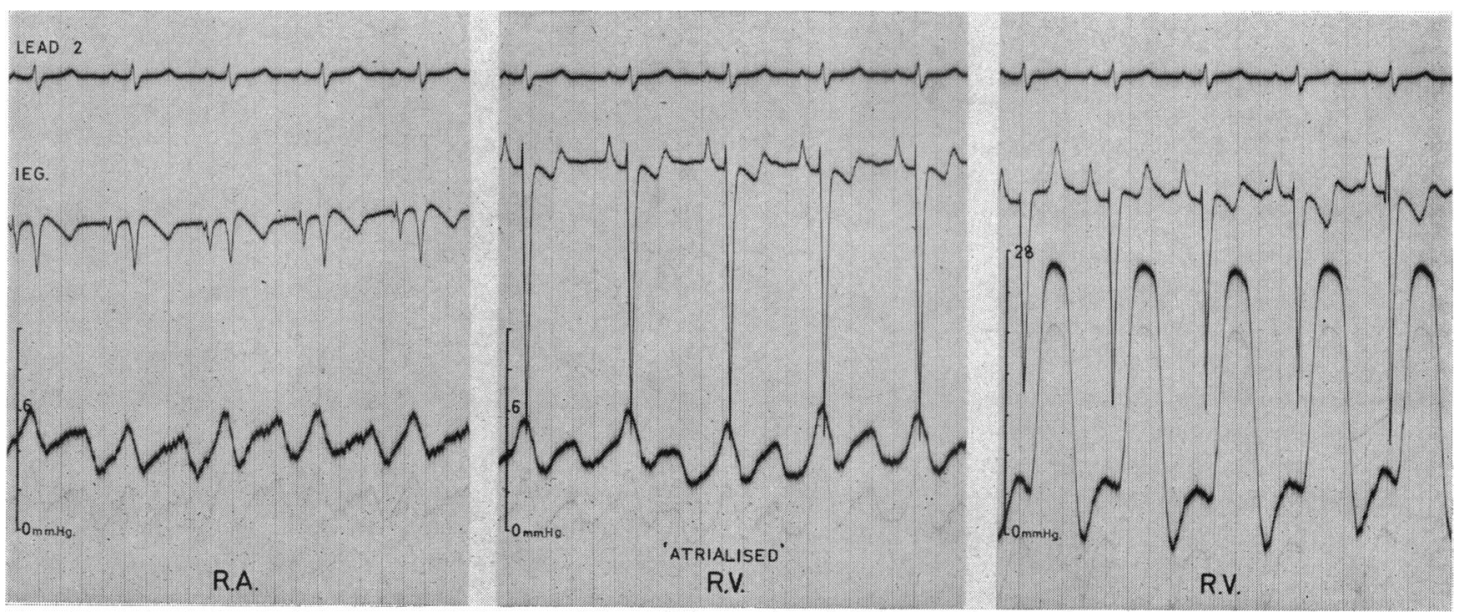

FIG. 2.-The type of tracing obtained in Ebstein's anomaly when a portion of the right ventricle has become "atrialised". In these circumstances a ventricular intracardiac electrocardiogram may be recorded with an atrial pressure pulse. 


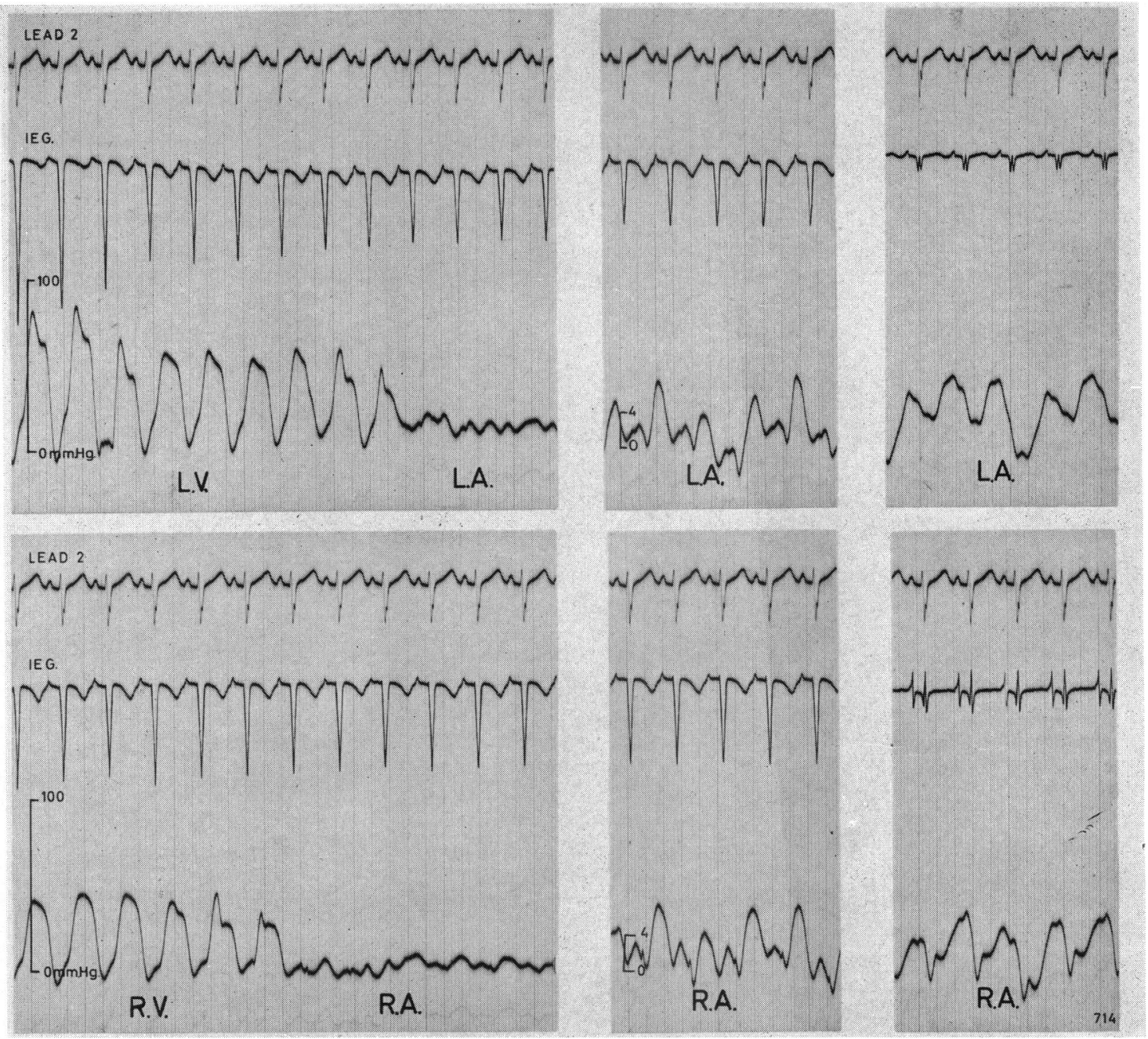

FIG. 3.- "Ebstein-like" tracings recorded on withdrawal through both the mitral and tricuspid valves in a patient who did not have Ebstein's anomaly.

catheterization in patients with Ebstein's anomaly is beyond doubt. They should, however, be considered with all the other clinical, electrocardiographic, and radiological features, and regarded as confirmatory rather than diagnostic, since by careful recording they may also be obtained in the absence of any abnormality of the tricuspid valve. The records illustrated in Fig. 3, for example, were made during right and left heart catheterization in a child with a ventricular septal defect and a probe patent foramen ovale, through which the left heart was entered. It will be seen that tracings of the sort said to be diagnostic of Ebstein's anomaly were obtained on withdrawal through both the tricuspid and the mitral valves. Intermediate zones, where a ventricular type electrocardiogram is present in association with an atrial pressure pulse, are clearly demonstrated on both sides of the heart.

With a little practice, such tracings can be recorded in most patients by anyone who knows his way about the inside of the heart with an electrode catheter. The tracings in Fig. 3 were deliberately recorded to demonstrate that high voltage QRS complexes can usually be picked up at the mouths of either of the A-V valves, if the catheter tip lies close to the septum where, as is demonstrated diagrammatically in Fig. 4, there are unbalanced ventricular potentials of considerable magnitude. 
This is in sharp contradistinction to the electrical field at the other side of the valve ring, which is near the outer border of the heart, and where much less powerful forces from the upper part of the free ventricular wall produce only low voltage $Q R S$ complexes such as are seen throughout the other parts of the atrial chambers.

The route taken by the electrode-tipped catheter, while the false positive Ebstein-like record illustrated in the lower half of Fig. 3 was made, is indicated in Fig. 5. Starting in the mid cavity of the right ventricle at point $A$, it was withdrawn through the tricuspid valve to point $B$ in the right atrium, where it lay close to the interventricular septum just above the $A-V$ valve ring, and where it continued to record a ventricular-like electrocardiogram in the presence of a right atrial pressure pulse. The other tracing shown in Fig. 5 was recorded entirely in the right atrium. This time, starting at a point $\mathrm{C}$ in mid atrium close to the lateral wall, the catheter was rotated through 180 degrees so that its tip came to lie once more in position B. This manœuvre again demonstrates that the normal intra-atrial electrocardiogram takes on a ventricular appearance as this particular area is approached, and this Figure has been designed to illustrate why positive withdrawal tracings may be accidentally recorded if the catheter tip passes through a normal tricuspid valve close to the septum.

It is of course true that in Ebstein's anomaly this transitional zone of discordant electrocardiographic and pressure signals will often begin well to the left of the midline, and if there is a long funnel-shaped abnormality of the tricuspid valve, such as the one seen in the angiocardiogram in Fig. 6, characteristic complexes from the atrialised portion of the ventricle may be recorded during a relatively long part of the withdrawal. The potentials responsible for the false positive records of the type illustrated in Fig. 3 and 5, on the other hand, are present only in a circumscribed area, and unless withdrawal is very slow, or is halted when they appear on the oscilloscope, the length of the transitional zone on the record is likely to be short.

During cardiac catheterization, however, and especially while recording withdrawal tracings, the catheter tip is liable to move very rapidly from one part of the heart to another. Sudden movements from the right ventricle into the right atrium are just as likely to occur in Ebstein's anomaly as in any other condition, and are probably the most common cause of false negative results. This is demonstrated in Fig. 7, which shows tracings recorded during the investigation of a patient with Ebstein's anomaly who also had mild pulmonary valvular stenosis. She had a long tubular deformity of her

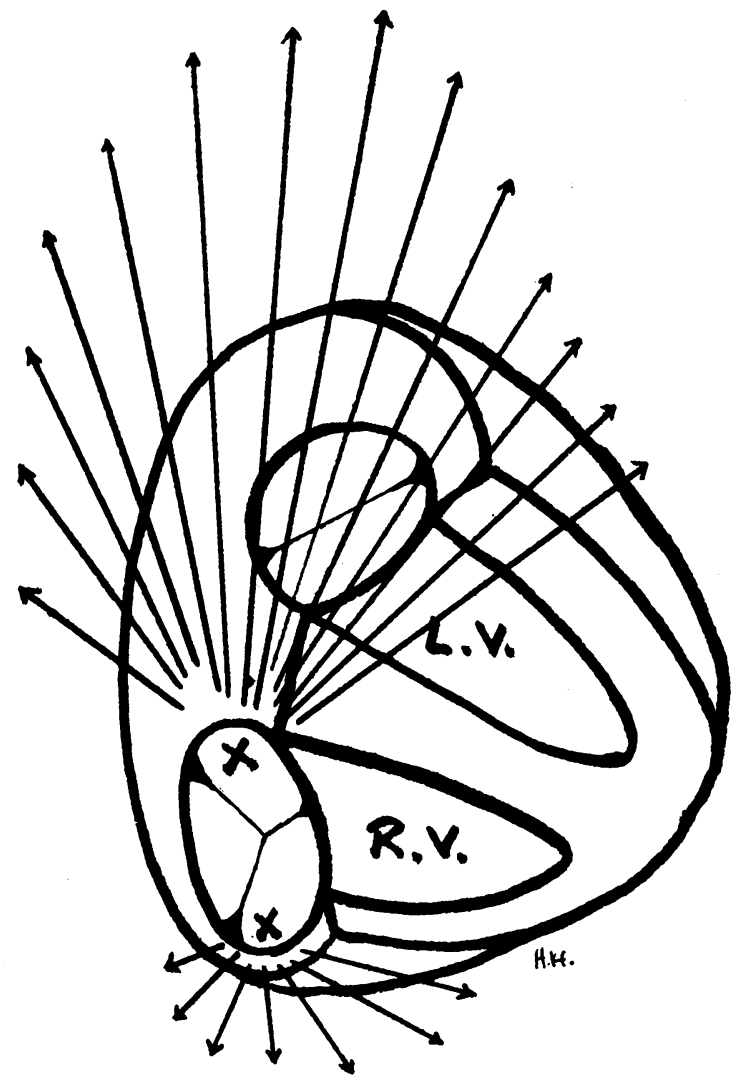

FIG. 4.-The difference in the magnitude of the unbalanced electrical forces on either side of the $A-V$ valve ring is shown diagrammatically. An electrode withdrawn through the tricuspid valve close to the septum may therefore continue to record ventricular potentials for a short time after it has entered the atrium.

tricuspid valve, which, during cine-angiocardiography, could be clearly seen to extend across to the lower end of the right ventricular outflow tract, as is shown diagrammatically on the postero-anterior radiograph of her heart. There was, therefore, a large atrialised portion in her right ventricle, which almost amounted to a third chamber and from which a typical Ebstein tracing (the lower of the two in Fig. 7), containing an intermediate zone with a ventricular electrocardiogram and an atrial pressure pulse, was recorded on withdrawal from $A$ to $B$. On another withdrawal, however, when the catheter tip took the short route out of the ventricle, it moved from the lower end of the outflow tract into the upper part of the right atrium, without recording a single complex in the transitional zone. Its course from $A$ to $C$ was characterized by one ventricular 


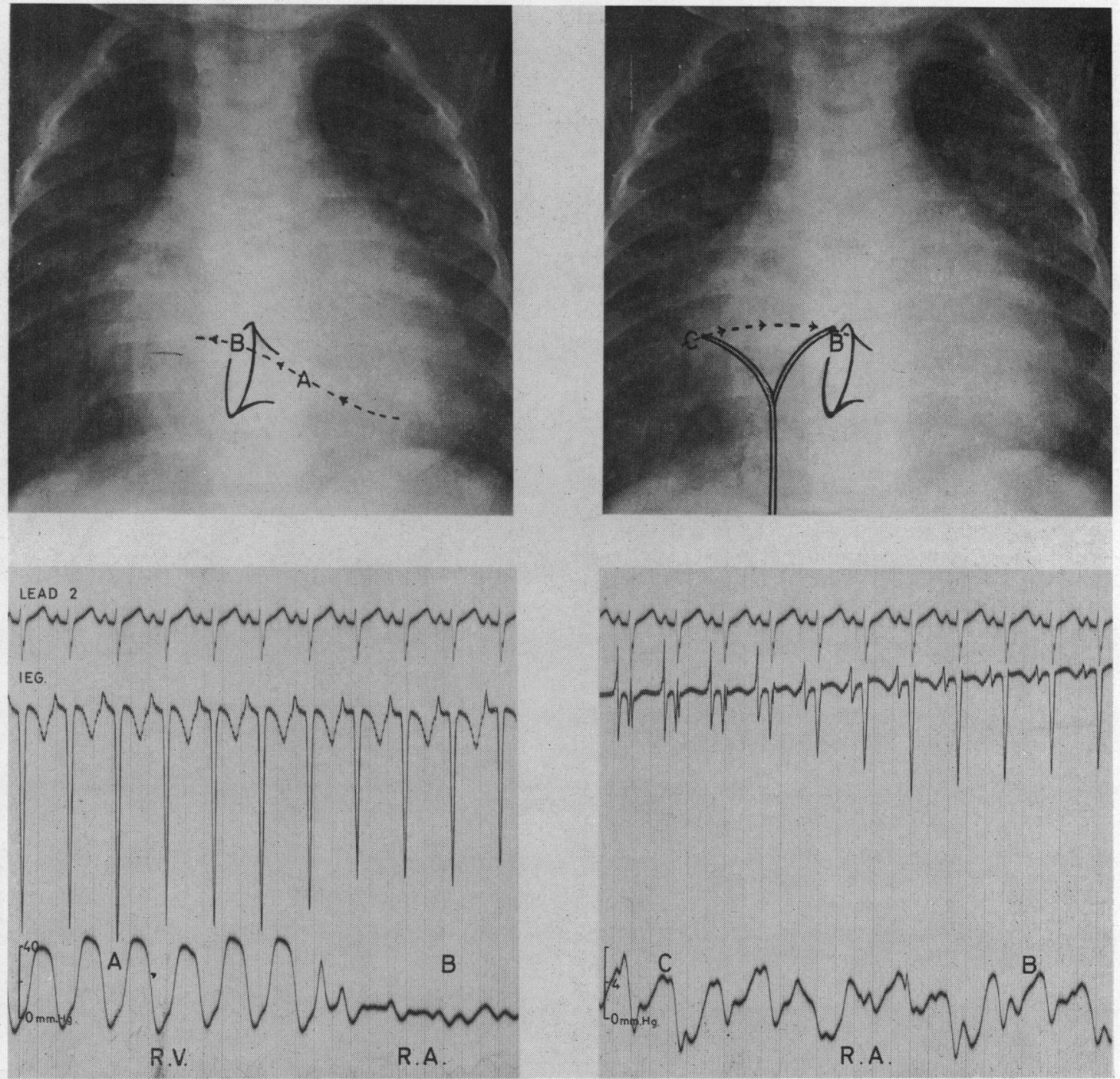

Fig. 5.-Withdrawal through the tricuspid valve from A to B has produced a false positive "Ebstein-like" record because the tip of the catheter bearing the electrode lies in the atrium close to the septum. The intracardiac electrocardiogram recorded in mid-right atrium during rotation of the catheter through $180^{\circ}$ from $\mathrm{C}$ to $\mathrm{B}$ again assumes a ventricular appearance as the upper part of the interventricular septum is approached.

ectopic beat as it turned the corner out of the infundibulum, one pressure pulse showing valve slap at the outlet of the atrialised ventricle, and thereafter it moved rapidly through the atrialized chamber into mid and upper atrium, where its course can be followed from the polarity of the atrial $P$ waves. This record, therefore, contains nothing to suggest a diagnosis of Ebstein's anomaly, and though multiple slow and careful withdrawals were made, the majority, like the upper of the two in Fig. 7, were false negative tracings.

The second feature of cavity potentials upon which the intracardiac electrocardiographic diagnosis of Ebstein's anomaly is based depends upon the fact that contact or injury currents occur when the electrode at the tip of a catheter touches the atrial or ventricular endocardium. Examples are shown in Fig. 8, where it will be seen that contact 

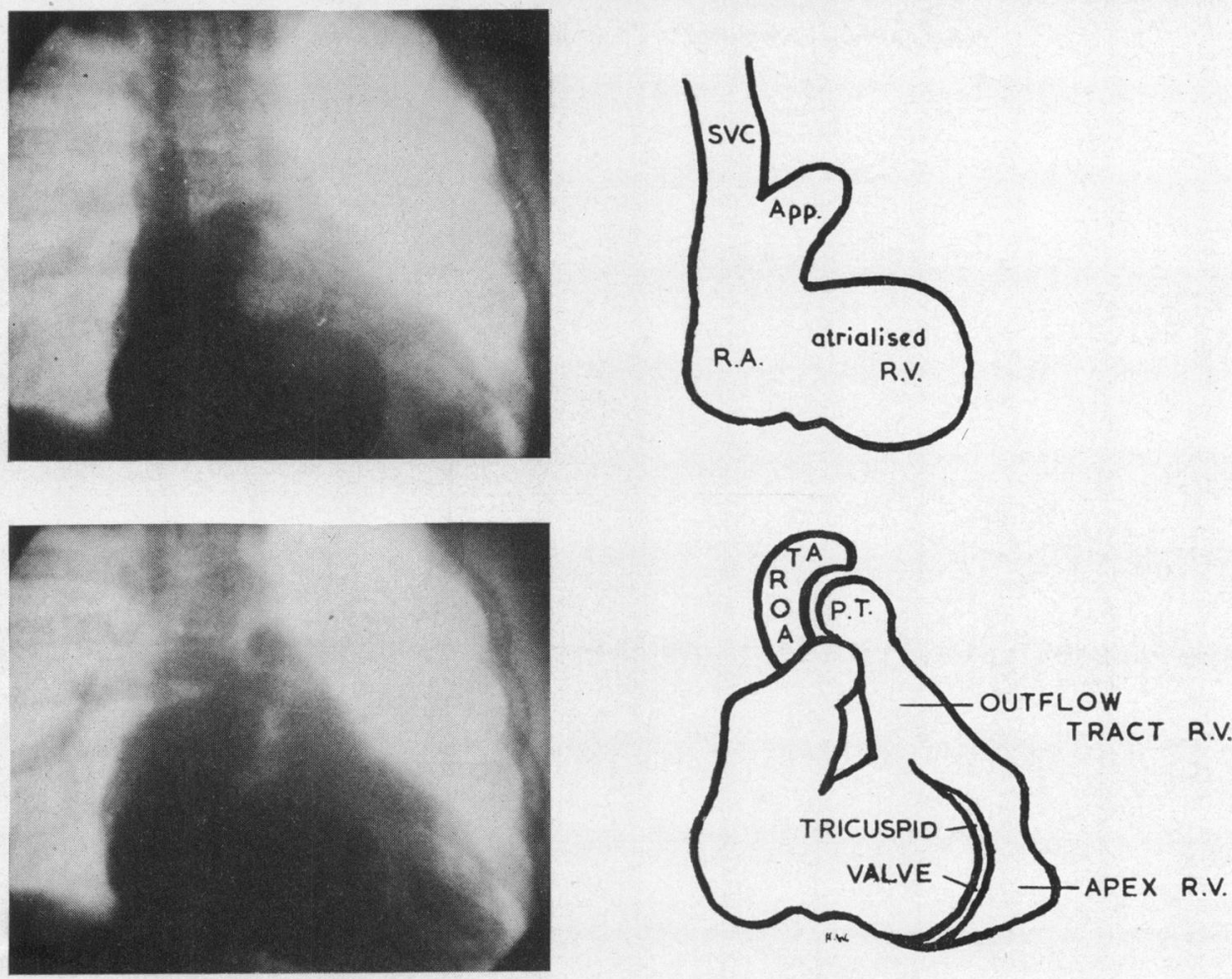

FIG. 6.-Frames excerpted from a cine-angiocardiogram in a patient with Ebstein's anomaly showing the greatly enlarged right atrium in which dense opacification persists even after the aorta has appeared on recirculation. The large atrialised portion of the right ventricle extends towards the apex, and the tricuspid valve, seen as a halo, is far to the left of the spine.

with the atrial wall produces elevation of the PT segments in the atrial electrocardiogram, and contact with the ventricular wall causes ST elevation in the ventricular electrocardiogram. It follows, therefore, that if an ST shift appears in a chamber where an atrial pressure pulse is being recorded, the cavity is surrounded by ventricular muscle: it was this combination that prompted Sodi-Pallares and Marsico to suggest in 1955 that electrode catheters might be of value in the investigation of those suspected of having this condition.

When present, they are certainly helpful, but I have been unable to record this phenomenon despite repeated attempts to do so during cardiac catheterization in six patients with Ebstein's anomaly. Its complete absence from multiple records taken when contact had been deliberately established was puzzling, and prompted a closer examination of the anatomy of the valvular deformity. From this it is clear that no two Ebstein valves are alike. In some the cusps are small, fenestrated, and abnormally inserted, but in others they are long, greatly thickened, sail-like structures, and arise from the annulus. Such valve tissue lying between the catheter and the right ventricular endocardium would effectively prevent the passage of contact currents between the electrode and the heart muscle. One can only assume that those who have recorded ST shifts in atrialised ventricular chambers have been lucky enough to pass the tip of the catheter through a fenestration in one of the valve cusps or to touch a small area of endocardium exposed by a rudimentary leaflet.

However, because partial damping is a frequent cause of pressure pulse artefacts on records made during cardiac catheterization, and because contact currents on simultaneously recorded intracardiac electrocardiograms frequently give warning of this possibility (Watson, 1962, 1964; Watson et al., 1964), all pressure pulses recorded in the presence of PT or ST elevations must be viewed with suspicion, since it is likely that the tip of the catheter is at least in partial contact with the wall of the heart. 


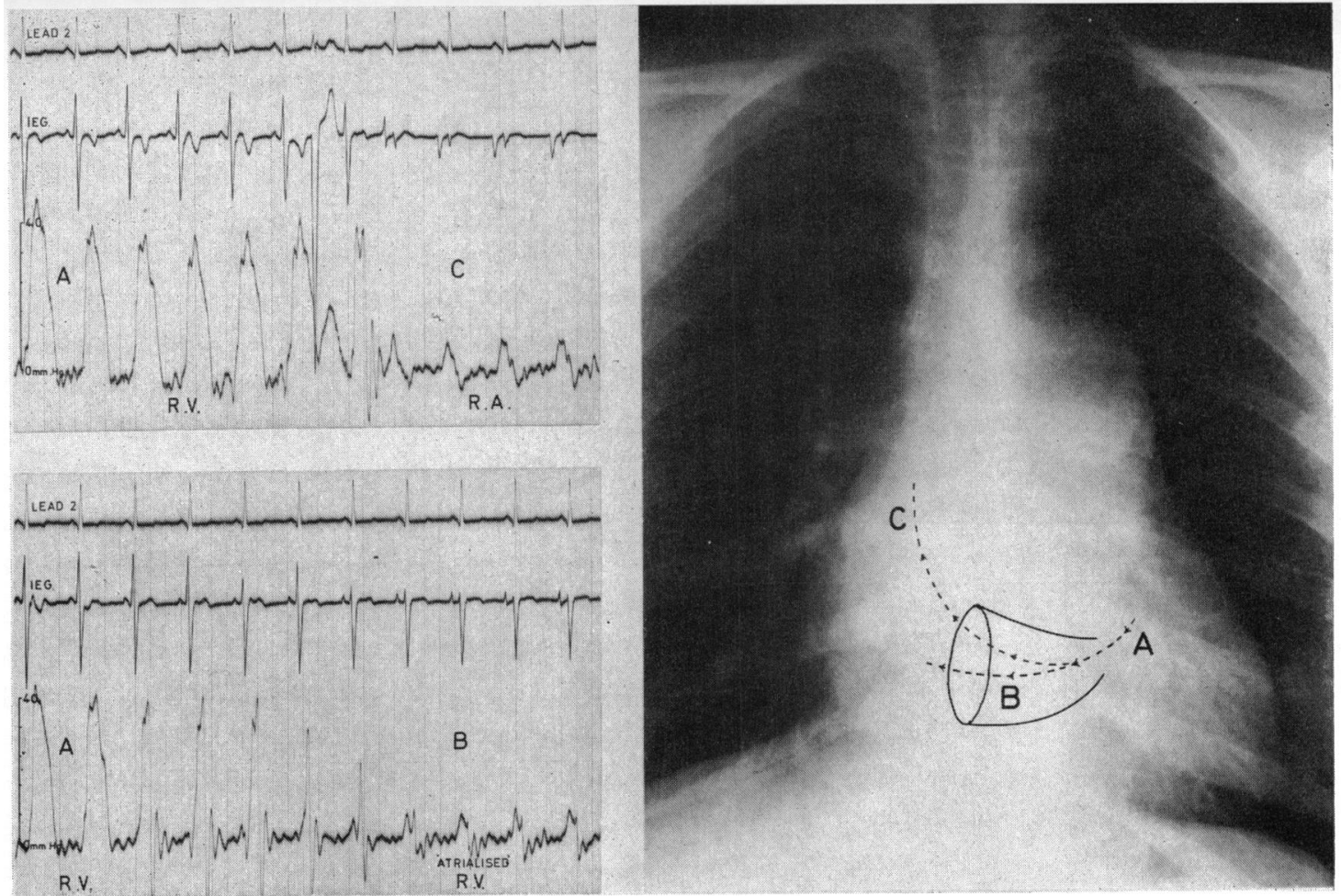

FIG. 7.-This demonstrates how false negative records may be obtained in patients with Ebstein's anomaly. The lower tracing was recorded on withdrawal from $A$ to $B$ as the catheter moved from the main cavity of the right ventricle into its atrialised portion, and shows the typical intracardiac electrocardiographic features of this condition. In the upper tracing the catheter moved very rapidly on withdrawal from the main cavity of the right ventricle (A) into the atrium proper $(C)$ without recording a single complex in the atrialised chamber, and there is nothing on this record to suggest or confirm the diagnosis of Ebstein's anomaly.

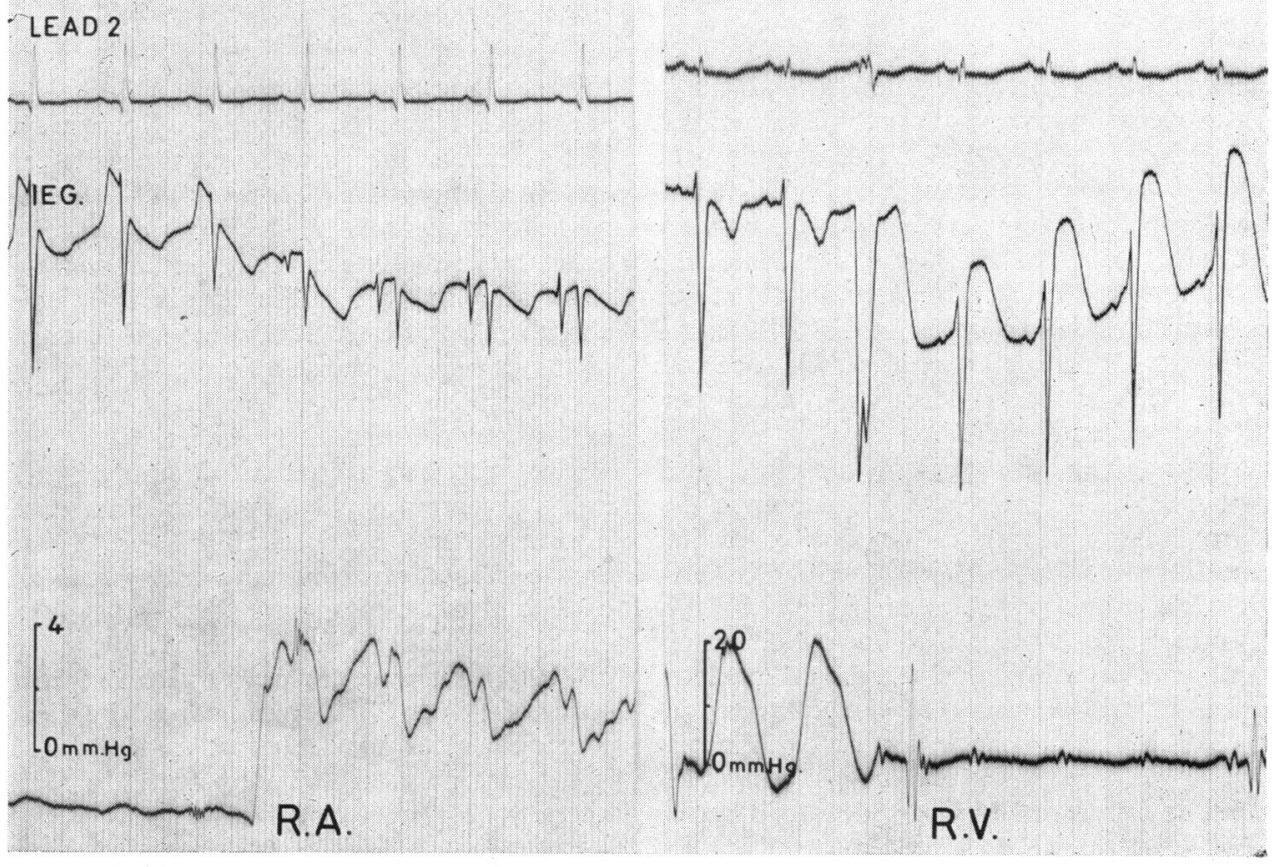

Fig. 8. - The effect of contact between the electrode and the endocardium. This results in PT elevation in the atrium and ST elevation in the ventricle. Such contact currents will identify the true nature of the chamber in which the tip of the catheter lies irrespective of the morphology of the complexes. 


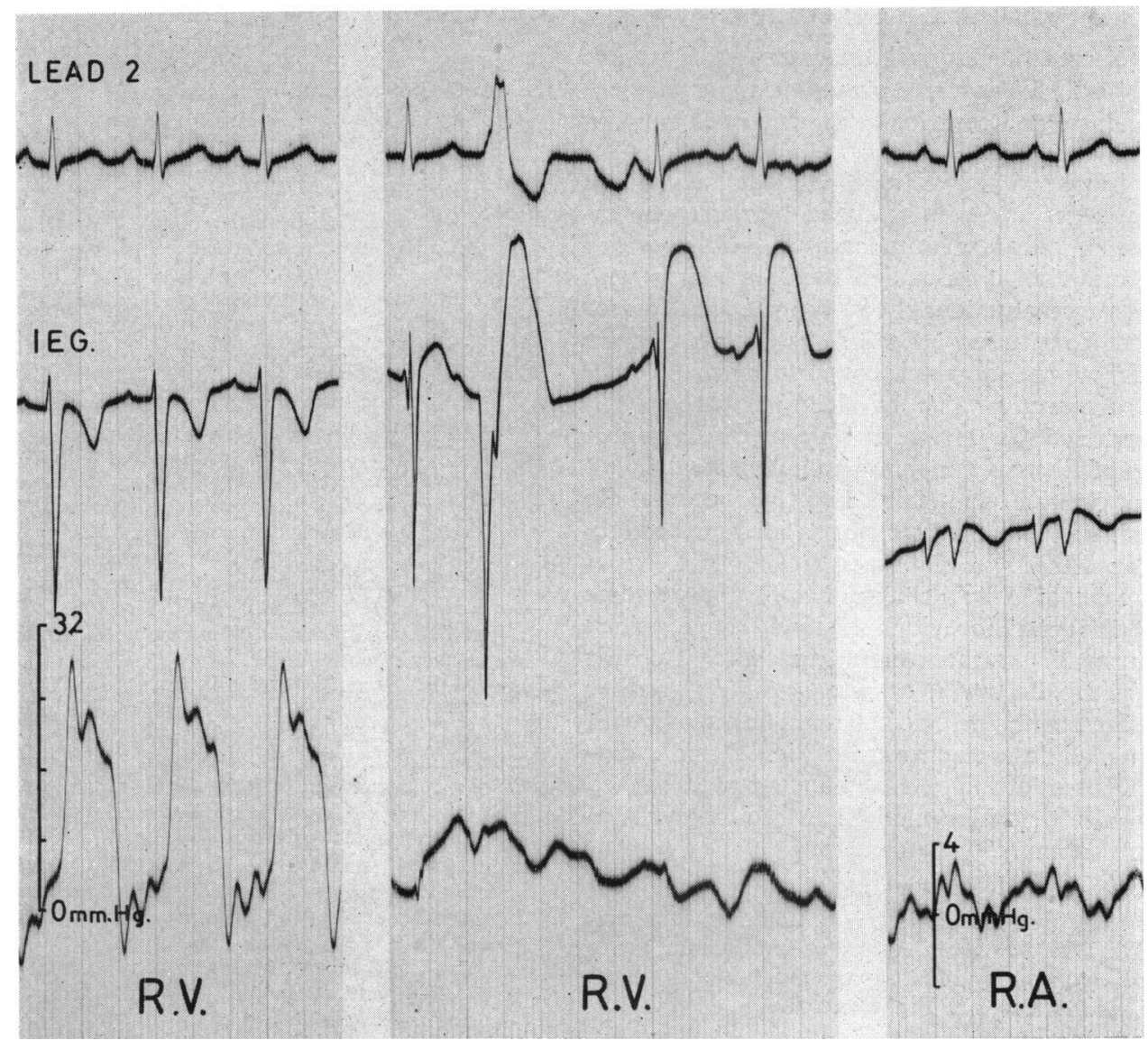

FIG. 9.-These records, made during cardiac catheterization in a child who did not have Ebstein's anomaly, demonstrate that a partially damped ventricular pressure may closely simulate an atrial pulse wave, and that ST elevations in the intracardiac electrocardiogram should warn of the possibility of pressure artefacts rather than suggest the diagnosis of Ebstein's anomaly. In this case the centrepiece was recorded in the apex of the right ventricle; the ST shifts subsided and a normal ventricular pressure pulse reappeared when the catheter was withdrawn.

After examining many tracings that are said to show ventricular contact currents and atrial pressure pulses, I am persuaded that though it does occur as a diagnostic sign in Ebstein's anomaly, it is infrequent, and that many such records could also be classified as false positives. Partially damped ventricular pressures may closely mimic atrial wave forms, as will be seen in Fig. 9 which has been made up to demonstrate how deceptive they may be and that it is often impossible to detect such distortions by timing the signals on the pressure channel from those on the electrocardiograph. The records were taken during cardiac catheterization on a child with a small ventricular septal defect, who had a normal tricuspid valve. The centre piece, mounted between typical mid-cavity records from the right ventricle and the right atrium, is a strip upon which a ventricular electrocardiogram showing gross ST elevations has been recorded along with an atriallike pressure pulse. The catheter tip, however, was in the apex of the right ventricle at the time, and whenever withdrawal began the contact currents disappeared and a normal ventricular pressure pulse reappeared. Under different circumstances such a record could easily be misinterpreted. On this record, there is a ventricular ectopic beat which has likewise produced an "atrial" pulse wave, and though this combination has also been said to indicate atrialisation of the ventricle, it too, as in this case, is much more likely to be an artefact. 


\section{SUMMARY AND CONCLUSIONS}

The successful surgical treatment of Ebstein's anomaly calls for accurate pre-operative assessment of the nature and severity of the tricuspid valvular lesion.

The increased risk of cardiac catheterization in this condition has been matched by increased experience of intracardiac techniques, and provided the examination is in skilled hands, patients with Ebstein's anomaly should be investigated in the same way as those with any other serious congenital heart lesion for whom surgery is contemplated.

The diagnostic value of electrode catheters is discussed, and the intracardiac electrocardiographic features of Ebstein's anomaly are illustrated.

False positive and false negative records are demonstrated and the mechanism of their production is explained.

It is concluded that, though helpful, intracardiac electrocardiographic evidence should be regarded as confirmatory rather than diagnostic. Records made with electrode catheters during cardiac catheterization should be considered only along with the other clinical, electrocardiographic, and radiological features of the case, and should not be relied upon as the definitive method in the diagnosis of Ebstein's anomaly.

I am grateful to Dr. Patrick MacArthur in Inverness and to Dr. David Short in Aberdeen for allowing me to have the opportunity of studying the patients whose records are illustrated in Fig. 6 and 7.

\section{REFERENCES}

Bahnson, H. T., Bauersfeld, S. R., and Smith, J. W. (1965). Pathological anatomy and surgical correction of Ebstein's anomaly. Circulation, 31, Suppl. 1, p. 3.

Baker, C., Brinton, W. D., and Channell, G. D. (1950). Ebstein's disease. Guy's Hosp. Rep., 99, 247.

Barnard, C. N., and Schrire, V. (1963). Surgical correction of Ebstein's malformation with prosthetic tricuspid valve. Surgery, 54, 302.

Bertrand, C. A., Zohman, L. R., and Williams, M. H. (1959). Intracardiac electrocardiography in man. Amer. $\mathcal{F}$. Med., 26, 534.

Blacket, R. B., Sinclair-Smith, B. C., Palmer, A. J., Halliday, J. H., and Maddox, J. K. (1952). Ebstein's disease: a report of five cases. Aust. Ann. Med., 1, 26.

Broadbent, J. C., Wood, E. H., Burchell, H. B., and Parker, R. L. (1953). Ebstein's malformation of the tricuspid valve: Report of 3 cases. Proc. Mayo Clin., 28, 79.

Brown, J. W., Heath, D., and Whitaker, W. (1956). Ebstein's disease. Amer. F. Med., 20, 322.

Caddell, J. L., and Browne, M. J. (1963). Right ventricular hypertension and pulmonary stenosis in Ebstein's anomaly of the heart. Amer. F. Cardiol., 11, 100.

Campbell, M. (1953). Editorial comment in-Henderson, C. B., Jackson, F., and Swan, W. G. A. Ebstein's anomaly diagnosed during life. Brit. Heart f., 15, 360.
Cartwright, R. S., Smeloff, E. A., Cayler, G. G., Fong, W. Y., Huntley, A. C., Blake, J. R., and McFall, R. A. (1964). Total correction of Ebstein's anomaly by means of tricuspid replacement. $\mathcal{F}$. thorac. cardiovasc. Surg., 47, 755.

Clark, L. C., Jr., and Bargeron, L. M., Jr. (1959). Left-toright shunt detection by an intravascular electrode with hydrogen as an indicator. Science, 130, 709.

Dickens, J., and Goldberg, H. (1958). Correlation of the precordial and endocardial ventricular electrocardiogram. Amer. Heart $\mathcal{F}$., 56, 8.

-, Maranhao, V., and Goldberg, H. (1959). Ventricular endocardial leads in left bundle branch block and left ventricular hypertrophy. Amer. F. Cardiol., 2, 472.

Dickerson, R. B., and Caris, T. N. (1959). Supplemental value of the intracavitary electrocardiograph in cardiac catheterization. Circulation, 20, 928.

Ebstein, W. (1866). Ueber einen sehr seltenen Fall von Insufficienz der Valvula tricuspidalis, bedingt durch eine angeborene hochgradige Missbildung derselben. Arch. Anat. Physiol. wiss. Med., p. 238.

Emslie-Smith, D. (1955). The intracardiac electrogram as an aid in cardiac catheterization. Brit. Heart F., 17, 219. , Lowe, K. G., and Hill, I. G. W. (1956). The intracardiac electrogram as an aid in the localization of pulmonary stenosis. Brit. Heart f., 18, 29.

Engle, M. A., Payne, T. P. B., Bruins, C., and Taussig, H. B. (1950). Ebstein's anomaly of tricuspid valve. Circulation, $1,1246$.

Ferrer, M. I., Harvey, R. M., Weiner, H. M., Cathcart, R. T., and Cournand, A. (1949). Hemodynamic studies in 2 cases of Wolff-Parkinson-White syndrome with paroxysmal A-V nodal tachycardia. Amer. F. Med., 6, 725.

Gandhi, M. J., and Datey, K. K. (1963). The value of electrophysiologic changes at the tricuspid valve in the diagnosis of Ebstein's anomaly. Amer. F. Cardiol., 12, 169.

Gasul, B. M., Weinberg, M., Jr., Luan, L. L., Fell, E. H., Bicoff, J., and Steiger, Z. (1959). Superior vena cavaright main pulmonary artery anastomosis. $\mathcal{f}$. Amer. med. Ass., 171, 1797.

-, Weiss, H., Fell, E. H., Dillon, R. F., Fisher, D. L., and Marienfeld, C. J. (1953). Angiocardiography in congenital heart disease correlated with clinical and autopsy findings. Amer. F. Dis. Child., 85, 404.

Giraud, G., Latour, H., Lévy, A., and Puech, P. (1951). L'électrocardiographie endocavitaire. Montpellier méd., 94, 487.

Glenn, W. W. L. (1958). Circulatory bypass of the right side of the heart. Shunt between superior vena cava and distal right pulmonary artery-report of clinical application. New Engl. F. Med., 259, 117.

Goodale, W. T., Levine, H. D., Bing, R. J., and Hackel, D. B. (1949). Electrocardiographic control of coronary venous catheterization in dogs and man, and simultaneous measurement of coronary blood flow, cardiac work and efficiency. National Meeting Amer. Fed. clin. Res., Atlantic City. (Abstract.) Amer. F. Med., 7, 412.

Goodwin, J. F., Wynn, A., and Steiner, R. E. (1953). Ebstein's anomaly of the tricuspid valve. Amer. Heart F., $45,144$.

Hardy, K. L., May, I. A., Webster, C. A., and Kimball, K. G. (1964). Ebstein's anomaly; a functional concept and successful definitive repair. $\mathcal{F}$. thorac. cardiovasc. Surg., 48, 927.

Hernandez, F. A., Rochkind, R., and Cooper, H. R. (1958). The intracavitary electrocardiogram in the diagnosis of Ebstein's anomaly. Amer. F. Cardiol., 1, 181. 
Kilby, R. A., DuShane, J. W., Wood, E. H., and Burchell, H. B. (1956). Ebstein's malformation: a clinical and laboratory study. Medicine (Baltimore), 35, 161.

Kjellberg, S. R., Mannheimer, E., Rudhe, U., and Jonsson, B. (1955). Diagnosis of Congenital Heart Disease. Year Book Publishers, Chicago.

Lev, M., Gibson, S., and Miller, R. A. (1955). Ebstein's disease with Wolff-Parkinson-White syndrome. Report of a case with histopathologic study of possible conduction pathways. Amer. Heart f., 49, 724.

Lillehei, C. W., and Gannon, P. G. (1964). Ebstein's malformation of the tricuspid valve: a method of surgical correction. Circulation, 30, Suppl. 3, p. 114.

$\longrightarrow$, and - (1965). Ebstein's malformation of the tricuspid valve: method of surgical correction utilizing a ball-valve prosthesis and delayed closure of atrial septal defect. Circulation, 31, Suppl. 1, p. 9.

McGredie, R. M., Oakley, C., Mahoney, E. B., and Yu, P. N. (1962). Ebstein's disease: diagnosis by electrode catheter and treatment by partial bypass of the right side of the heart. New Engl. F. Med., 267, 174.

Mayer, F. E., Nadas, A. S., and Ongley, P. A. (1957). Ebstein's anomaly: presentation of ten cases. Circulation, 16, 1057.

Moles, S. S., Jacoby, W. J., Jr., and McIntosh, H. D. (1964). Ebstein's malformation. Discordant intracavitary electrocardiographic and pressure relationship. Amer. F. Cardiol., 14, 720.

Reed, W. A., Kittle, C. F., and Heilbrunn, A. (1963). Superior vena cava-pulmonary artery anastomosis. Arch. Surg., 86, 87.

Schaede, A. (1951). Zur Diagnostik des Ebstein-Syndromes. Dsch. Arch. klin. Med., 198, 619.

Schiebler, G. L., Adams, P., Jr., Anderson, R. C., Amplatz, K., and Lester, R. G. (1959). Clinical study of twentythree cases of Ebstein's anomaly of the tricuspid valve. Circulation, 19, 165.

Scott, L. P., III, Dempsey, J. J., Timmis, H. H., and McClenathan, J. E. (1963). A surgical approach to Ebstein's disease. Circulation, 27, 574.

Sodi-Pallares, D., Acevedo, J. S., Cisneros, F., Marsico, F., and Alvarado, A. (1954). Wolff-Parkinson-White syndrome in Ebstein's disease: possibility of diagnosing this anomaly by means of intracavitary leads. In Official Program, Part II: Abstracts of Scientific Papers, 2nd World Congress of Cardiology, and 27th Annual Scientific Sessions of the Amer. Heart Assoc., Washington, D.C., 1954, p. 162. Stuyvesant Press, New York.

—, and Marsico, F. (1955). The importance of electrocardiographic patterns in congenital heart disease. Amer. Heart F., 49, 202.

Steinberg, M. F., Kroop, I. G., and Grishman, A. (1952). The value of intracardiac and esophageal leads in the analysis of complex arrhythmias. f. Mt Sinai Hosp., 18, 337.

Tourniaire, M., Deyrieux, F., and Tartulier, M. (1949). Maladie d'Ebstein: essai de diagnostic clinique. Arch. Mal. Cour, 42, 1211.

Vacca, J. B., Bussmann, D. W., and Mudd, J. G. (1958). Ebstein's anomaly. Complete review of 108 cases. Amer. F. Cardiol., 2, 210.

Watson, H. (1962). Intracardiac electrography in the investigation of congenital heart disease in infancy and the neonatal period. Brit. Heart f., 24, 144.

- (1964). Electrode catheters and the diagnostic application of intracardiac electrography in small children. Circulation, 29, 284.

—, Breckenridge, A. M., and Lowe, K. G. (1964). Right ventricular pressure flow relationships and intracardiac Venturi effects in Fallot's tetralogy. Brit. Heart f., 26, 794.

- , and Lowe, K. G. (1962). Ventricular pressure flow relationships in isolated pulmonary valvular stenosis. Brit. Heart F., 24, 431.

$\longrightarrow$, and - (1965). Functional adaptations of the right ventricular outflow tract in congenital heart disease. Brit. Heart f., 27, 408.

—, Pickard, C., Lowe, K. G., and Hill, I. G. W. (1960). Cine-angiocardiographic studies of the outflow tract in isolated pulmonary valvular stenosis. Brit. Heart $\mathcal{F}$., $22,706$.

Wood, P. (1956). Diseases of the Heart and Circulation, 2nd ed. Eyre and Spottiswoode, London.

Yim, B. J. B., and Yu, P. N. (1958). Value of an electrode catheter in diagnosis of Ebstein's disease. Circulation, 17, 543. 